\title{
Risk Observatory-A Tool for Improving Safety and Health at the Workplace
}

\author{
Karin Reinhold \\ Marina Järvis \\ Pila Tint \\ Tallinn University of Technology, Tallinn, Estonia
}

The main problems in occupational health and safety (OHS) system in Estonia (a postcommunist new European Union Member State) are analyzed and the implementation of a simple, flexible risk assessment method is presented. The study aimed to assess the working environment, the employers' possibilities and willingness to carry out risk assessment, ways to manage risks and the steps being taken towards progressive improvement in OHS. The role of the Estonian Labour Inspectorate in the risk observatory is that of the main key authority in data collection and information dissemination in OHS.

$$
\text { occupational health and safety risk assessment working conditions }
$$

\section{INTRODUCTION}

This article provides an in-depth analysis of a postcommunist new European Union (EU) Member State, Estonia, situated in the Baltic region, on the southern shores of the Gulf of Finland. Despite its physical proximity to its northern Scandinavian neighbour of Finland, Estonia lacks many progressive features of the system of safety culture and risk assessment which prevails there [1]. The purpose of this paper is to illustrate the contours of a gulf which constitutes not merely a geographic separation, but a separation of standards in occupational health and safety. We attempt to illustrate this theme by workplace-based data on risk assessment and risk management and to assess the steps being taken towards progressive improvement in occupational health and safety (OHS).

Estonia is one of the smallest countries in the enlarged EU (population: 1.4 million; labour force: 600000). Like many other European countries, especially postcommunist ones, it has an aging labour force, which poses ongoing problems in terms of meeting urgent changes in the economy. Work pressure and the stress in daily life are perceived as creating health problems both at the workplace and during leisure time.

The incidence of occupational diseases is a specific indicator of existing hazards and risk factors in the working environment. In Estonia, occupational diseases are mainly registered in their later stages when the patient is already incapacitated. The main causes of occupational diseases at present are identified as arising from lifting heavy loads and from repetitive forms of work. Both cause musculoskeletal disorders.

\section{RISK ASSESSMENT IN THE WORKING ENVIRONMENT}

Risk assessment in the working environment has been a topic for Estonian OHS researchers since 1996, i.e., since the publication of "Guidance of risk assessment at work" [2]. The OHS Act, which

\footnotetext{
The authors of this paper would like to thank Charles Woolfson, Professor of Labour Studies at the University of Glasgow, UK, for his professional assistance and valuable work in reviewing the present article.

Correspondence and requests for offprints should be sent to Piia Tint, Tallinn University of Technology, Kopli 101, 11712 Tallinn, Estonia. E-mail: <piia.tint@tv.ttu.ee>.
} 
requires risk assessment to be carried out at every workplace, was adopted in Estonia in 1999 [3].

Existing risk assessment models (based on Standard No. BS 8800:1996 [4]) indicate the need to determine the probability of occurrence and the severity of the consequences of the impact of hazardous factors on the worker. It is difficult for employers to determine those probabilities (in Estonia risk assessment can be carried out by employers or by a person or an office recognized by the Health Care Board). Pekkarinen has discussed some versions of risk assessment in Standard No. BS 8800:1996, where the probabilities are clearer for the user [5]. The need to set correlations between exposure time and stages of occupational diseases is very obvious. Rantanen has developed a model for determining the level of risk for chemical hazards (considering exposure limits in Standard No. BS 8800:1996 [4]) [6].

A simple, flexible risk assessment method has been worked out at the Tallinn University of Technology [7]. It is based on a two-step model that can be enlarged. This model offers every enterprise an opportunity to choose a suitable and feasible scheme for implementation into practice. The practical use of the model is given in section 4 .

\section{THE ACTIVITIES OF THE NATIONAL LABOUR INSPECTORATE (NLI) IN RISK OBSERVATORY}

The NLI is the main and the only administrative body in OHS in Estonia. It provides surveillance over legislative compliance, records occupational accidents and diseases on a yearly basis, and inspects hazards in the working environment. As there are $\sim 60000$ small and medium-sized enterprises (SME) in Estonia, the NLI (with only $\sim 40$ labour inspectors) has the capacity to inspect only those which deal with hazardous activities or where a serious accident has been reported. Like in many other European countries, SMEs are a problem area for Estonian OHS because their owners often lack knowledge on risk assessment and risk management.

\subsection{The Situation in OHS in 2002}

This section compares the working environment issues in Estonia in 2002 [8] and 2006 [9]. This analysis shows how the goals for improving working environment have changed during those 5 years.

The strategy for the Estonian OHS for 20022006 tried to follow the EU strategy for that period [10]. The NLI plans its future annual activities on the basis of the results of working environment assessments and an analysis of occupational accidents and diseases registers of the current year, including the implementation of campaigns proposed by the European Agency for Safety and Health at Work, e.g., on construction safety.

Since 1999, when the OHS Act came into force, the NLI has exercised systematic control over compliance with the requirements of the law in companies and institutions. Considering the variety and the level of hazards in Estonian enterprises and taking into account the human capacity of the NLI (100 workers, 40 of them labour inspectors), state supervision and working environment assessment covered first and foremost larger enterprises with more hazardous fields of activity. The frequency of inspection of these enterprises in the future is to be determined by the level of hazards identified in the enterprises during previous assessments.

Assessment of the working environment in enterprises is a labour- and time-consuming activity. Therefore, target inspections or campaigns are planned and carried out each year with the aim of covering as many enterprises as possible where there is a likelihood of specific OHS problems. During target inspections measures are taken to eliminate or to reduce the hazards and health risks.

Inspection priorities and objectives for 2002 were as follows:

- to ensure that the working environment complies with the requirements of legal acts regulating OHS in enterprises with more hazardous working environments (manufacturing industry; mining industry; construction; electricity; gas and water supply; 
transport, storage and communication; fishery; forestry and agriculture);

- to inspect and assess those enterprises in hazardous areas of activity with 10-19 employees that were not inspected in 2001;

- to inspect new and reconstructed buildings and to advise employers as to what is needed to ensure workplaces [11] and work equipment [12] comply with OHS requirements and that work arrangements are in line with the requirements of legal acts;

- to inspect activities focussed on risk assessment in the food industry to reduce the risk caused by physiological factors, thus primarily improving the working conditions of female workers;

- to inspect implementation of the requirements of the working and rest time act (WRTA) [13] and the employment contracts act (ECA) [14] to ensure that the requirements of the legal acts regulating labour relations in the construction industry are followed, thus preventing incapacity and illness of construction workers caused by physical and psychological stress;

- to inform employers who cannot be directly inspected in 2002 about of new legal acts regulating $\mathrm{OHS}$ and labour relations, thereby directing employers' activities towards complying with the requirements and, as feedback, obtaining information from the employers of the measures taken to improve the working environment in the enterprises;

- to continue the inspections in the enterprises with more hazardous areas of activity (as revealed by inspections in 2001); enterprises where there were serious or fatal occupational accidents, or where cases of occupational diseases were registered; in the course of follow-up inspection, to assess the changes that have taken place in the working environment and assess the results of activities to prevent accidents and ill health at work.

Four types of inspections (general, advisory, target and follow-up) were carried out by the NLI. In 2002, 4734 enterprises were inspected; in 1661 of them the employer's activity was assessed in terms of compliance with legal obligations, and in 1358 the working environment as a whole was assessed (general inspection). Inspection of compliance with legal acts regulating labour relations was also carried out during general OHS inspections, and in 597 enterprises, during target or follow-up inspections. During advisory inspections 669 employers were informed of new OHS-related legal acts.

Target inspections concerning the assessment of physiological risk factors took place in 102 enterprises in the food industry, and in 132 enterprises and on 162 construction sites, where they concerned WRTA [13] and ECA [14] requirements. The reports of the target inspections were submitted to the Ministry of Social Affairs and to the respective employers' and employees' organizations to promote social dialogue.

In 1508 new or reconstructed buildings compliance with OHS requirements was assessed through inspection before local government authorization for use were granted and compliance of personal protective equipment (PPE) with safety requirements was assessed in 65 enterprises. During these inspections work was halted in 24 cases where it was assessed as dangerous to the life of workers or other persons near-by and in 88 cases the use of life-threatening work equipment was forbidden.

The causes and circumstances of 839 serious and 26 fatal occupational accidents were investigated in collaboration with the police and labour inspectors who participated in the investigation of 236 serious occupational accidents, of which 141 resulted in prosecution for OHS law violations. In addition, 98 cases of occupational disease were investigated with the participation of occupational health doctors (of whom there are $\sim 100$ in Estonia).

Advice was given by the inspectors to 6613 employers and 10652 employees or their representatives as to how to solve problems concerning OHS and labour relations. A total of 418 written petitions of employees were examined and resolved. On the basis of the ECA [14] and WRTA [13] 6791 applications to conduct commercial operations were granted to employers concerning 57844 employees. In 801 cases such applications were rejected. 
For violation of the requirements of legal acts administrative penalties were imposed on 184 natural persons (individual employers or their representatives), the total sum of fines: 138880 EEK (8860 EUR); and to 30 legal persons (registered commercial legal entities), the total sum of fines: 185000 EEK (11800 EUR). This gives an average of penalties imposed as 48 EUR and 393 EUR, respectively, during this period.

\subsection{The Report in 2006}

NLI's report for 2006 shows the changes in OHS goals during the first years of Estonia's membership in the EU. NLI's priorities in 2006 were as follows:

- surveillance of major hazardous enterprises and as many as possible enterprises using hazardous chemicals; enterprises with potentially explosive atmosphere and where overall control had not been carried out in 2003-2005;

- surveillance of other hazardous activities (wood processing; processing of metals, equipment and machines; chemicals or chemical products; food processing) and enterprises where there had been accidents in the past 2 years.

In 2006 the problem of asbestos was highlighted. In this context 32 asbestos-using workplaces were checked, of which 18 were engaged in manufacturing asbestos-cement products and 9 in asbestos management. Inspections were done in co-operation with Finnish and Estonian OHS researchers.

Surveillance in 2006 was intensive with 5982 NLI inspections, an increase of $26 \%$ from 2002 and 19\% from 2005. Over 3300 employers received formal notifications of OHS requirements to be met. General inspections were carried out in 824 enterprises, a decrease of $39 \%$ from 2002 and 44\% from 2005.

Target inspections were made in 2592 enterprises (the day of inspection was not announced in 1162 visits). A new method of inspection was also developed: speed inspection. This kind of control which involves a brief visit of up to one hour by a labour inspector in accordance with a list of medium to low risk working environments (according to a list compiled by NLI) was carried out in 1034 enterprises. The number of follow-up inspections where violations were noted increased from 717 to 804 from the previous year.

The different distribution of inspection activities carried out by the NLI in 2006 compared to 2002 was as follows: general inspection: $16 \%$ (28\% in 2002); speed inspections: $17 \%$ (nonexistent in 2002); target inspections: $43 \%$ (35\% in 2002); inspection of new buildings: $12 \%$ (31\% in 2002); follow-up inspections: $12 \%$ (6\% in 2002).

During the inspections, 11666 legislation violations were found; 8655 orders for remedial action were issued and 3011 recommendations were compiled to help employers to improve the working conditions.

The pattern of violations, with failure to carry out risk assessment in the first place, comprised (a) risk assessment not carried out by the employer, 1633 cases (11\%); (b) internal audit not carried out, 1286 (8\%); insufficient training and safety instructions, $992(6 \%)$; safety instructions not compiled, 813 (5\%); nobody elected and trained to be responsible for first aid, $730(5 \%)$; and no safety representatives elected $619(4 \%)$.

Several conclusions emerged from these data:

- employers did not ensure OHS in the workplace was at the required level;

- co-operation between employers and employees on OHS matters was insufficient;

- deficiencies in OHS systems in enterprises continued to cause accidents and occupational diseases.

The following pattern emerged in an analysis of legislative violations in the use of work equipment and in the organization of work tasks:

- in 965 cases, the work tools did not correspond to the norms; of those, in 283 instances, equipment did not correspond to the safety demands, and in a further 123 instances, safety control equipment was out of order; 
- in 1007 cases, workrooms and workplaces (including computer workstations and pathways) were not arranged in accordance with the legislation;

- in 232 cases, hazardous areas, pathways and containers were not properly identified.

The following pattern emerges from an analysis of legislative violations concerning environmental hazards:

- in 417 cases, there were violations concerning chemical usage (including cases where chemical safety cards were absent, contamination in the workrooms was not measured, requirements for working in explosive environments not followed;

- in 355 cases, the legislation act on lifting heavy loads [15] was not followed and risk analysis was not conducted;

- in 223 cases, measures to decrease harmful physical environmental factors were not followed, e.g., lighting was below stipulated norms.

The strategy of inspection (first, primary inspection and, if the NLI inspector deemed it necessary, a follow-up inspection) worked. Most employers corrected their mistakes by the followup inspection.

During the primary inspection the enterprises were divided into three groups according to how safe the working conditions were: low (22\%), medium (58\%) and high risk (20\%). During the follow-up inspection the inspectors noted that the proportion of low risk enterprises increased and of medium and high risk enterprises decreased (Figure 1).

\subsection{Changes in 2002-2006}

Risk assessment as a tool for decreasing occupational accidents and diseases was emphasized between 2002 and 2006. NLI's strategy changed to more target inspections than unannounced visits to enterprises. The number of occupational accidents increased (from 3115 in 2002 to 3651 in 2006). The size of the workforce changed from 585500 (532 accidents per 100000 workers) to 646300 (565 accidents per 100000 workers) during this period. It would appear that fewer accidents were hidden. The number of fatal accidents decreased marginally from 5.0 to 4.5 per 100000 workers as there were

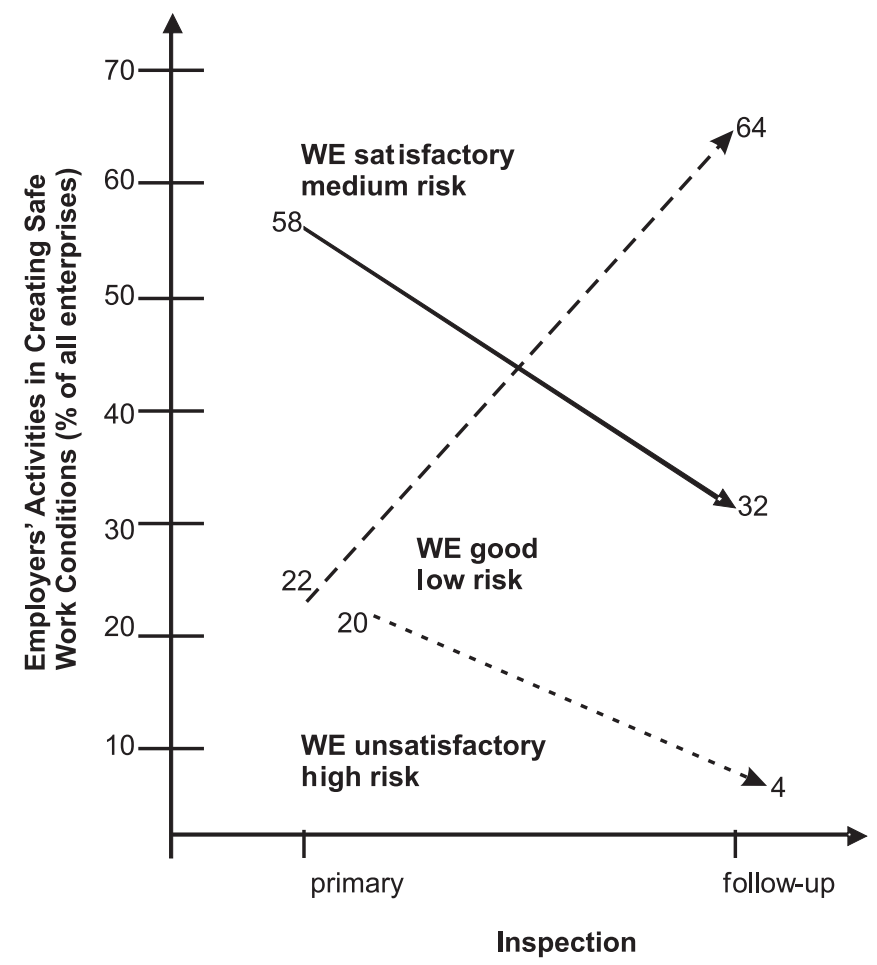

Figure 1. National Labour Inspectorate's assessment of the impact of primary and follow-up inspections. Notes. WE-working environment. 
fewer industrial activities (mostly construction work).

In the next section we show the practical use of the risk assessment model in industrial and office environments.

\section{THE PRACTICAL PART OF THE INVESTIGATION}

The Ergonomics Laboratory of the Tallinn University of Technology carried out risk analysis in 143 Estonian enterprises and offices in 20022008. About 3000 workplaces were investigated. In most cases, the risk assessment method was based on Standard No. BS 8800:1996 [4]. In addition, workers' opinions on hazards in their working environment were gathered $[16,17,18]$.

\subsection{Analysis of Working Conditions in the Wood Processing industry}

The working environment in a large woodprocessing firm (1000 workers) in a mediumsized town in Estonia was analyzed. A list of hazards had been compiled prior to the investigation by the firm's working environment specialist with over 20 years' work experience in this factory. The main risk factors were hazardous tools and equipment, heavy physical load (moving wheelbarrows), noise, wood dust and, occasionally, chemical odours (e.g., formaldehyde) originating from polishes. Some indication of the overall level of safety culture can be gained from the discovery that one protective metallic machine guard for protection against cut injuries to fingers had been removed and replaced by cardboard. This type of accident has predominated in Estonian work traumas in recent years $(\sim 500$ cut injury traumas of fingers per year are reported, including amputations).

Hazards were measured in the polishing and varnishing department: air temperature: $19.8{ }^{\circ} \mathrm{C}$; air humidity: 42.0\%; lighting (overall): $300 \mathrm{~lx}$; wood dust concentration: (a) $\sim 1.5 \mathrm{mg} / \mathrm{m}^{3}$ overall in the department, (b) $10.0 \mathrm{mg} / \mathrm{m}^{3}$ near the machines; noise: $98.0-101.2 \mathrm{~dB}(A)$; concentration of formaldehyde (as a component of phenolformaldehyde varnish), an 8-h mean: $0.5 \mathrm{mg} / \mathrm{m}^{3}$.
Vibration caused by wood-processing equipment was not measured. However, the vibration disease in the wood industry in Estonia is rather high (one of the two most frequent occupational diseases, alongside physical overload).

On the basis of the measurements and observations in the department the following conclusions were made.

- The microclimate in the polishing and varnishing department met the requirements; however, it would be reasonable to raise the moisture content of the air to avoid workers' complaints of itchy eyes and dry skin.

- Noise was above the limits, $85 \mathrm{~dB}(A)$, in every workstation measured, but work breaks were taken and earmuffs were used. Thus, the total amount of noise during an 8-h workday did not exceed the permissible level (dose: $85 \mathrm{~dB}(A) \times 8 \mathrm{~h}$ ).

- Phenol-formaldehyde varnish is an allergen. The risk phrases for this compound are R23/24/25, R34, R40, and R43 [19, 20]. The exposure limits $\left(0.6 \mathrm{mg} / \mathrm{m}^{3}\right)$ were not exceeded, but the welfare of sensitive workers has to be considered.

- The safety of machines has to be taken into consideration when buying new equipment. Experience shows that even machines with CE-mark can cause traumas if used incorrectly.

The 5-step simple, flexible risk assessment model was used for assessing working conditions (Figure 2).

\subsection{Analysis of Working Conditions in the Textile Industry}

The working environment in a middle-scale textile firm (200 workers) in Tallinn was analyzed. The list of hazards was compiled before the investigation by the working environment specialist of the enterprise.

The main risk factors in the textile industry include hazardous tools and equipment, heavy physical load and adverse ergonomics primarily for female workers, noise and textile dust. Hazards were measured in different departments (sewing, cutting 


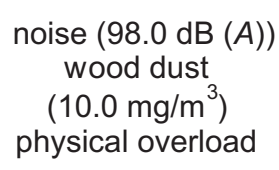

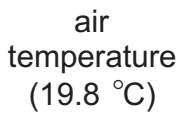

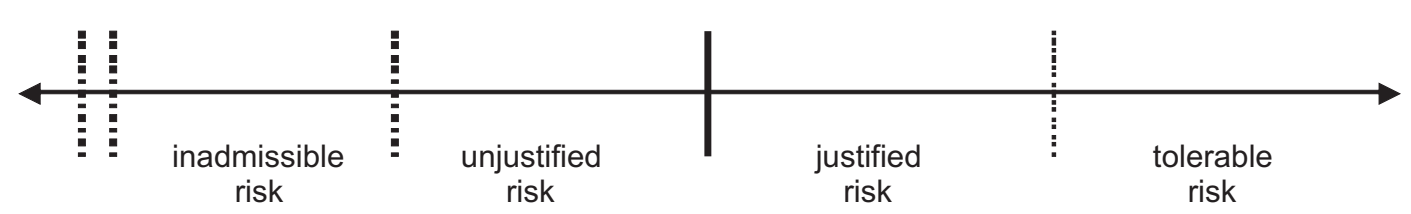

Figure 2. Assessment of the working conditions with a simple risk assessment method in the wood processing industry.

and embroidering): air temperature: $20.0-26.7^{\circ} \mathrm{C}$; air humidity: 33.0-38.0\%; lighting: 160-1900 lx; textile dust concentration: (a) $\sim 0.4 \mathrm{mg} / \mathrm{m}^{3}$ overall in the department, (b) $1.0 \mathrm{mg} / \mathrm{m}^{3}$ near the machines; noise: $70.0-89.5 \mathrm{~dB}(A)$.

Because of the possibility of accidents/traumas originating from machines, it was declared that there were hazards for finger traumas. As mentioned before, those traumas are frequent in Estonia. Therefore, the safety of equipment has to be taken into consideration when purchasing new sewing and button machines.

On the basis of the measurement and observations in the department the following conclusions were made.

- The microclimate in the textile firm was satisfactory (although there was still scope for improvement by raising air humidity and providing better ventilation).

- Noise was under the permissible limits, $85 \mathrm{~dB}(A)$, in most workplaces, only in a few areas was it higher than $85 \mathrm{~dB}(A)$, but breaks were taken and earmuffs were used if necessary.

- Therefore, the total amount of noise during an 8-h workday did not exceed the permissible level (dose: $85 \mathrm{~dB}(A) \times 8 \mathrm{~h}$ ).
The 5-step simple, flexible risk assessment model was used for the assessment of working conditions (Figure 3).

Most of the offices investigated belonged to industrial companies, but workrooms of educational institutions (kindergartens, schools and the Tallinn University of Technology) were investigated, too.

The working conditions in offices, where people spend whole workdays in front of video display units (VDUs), vary greatly between seasons because of changes in overall ambient lighting. Poor knowledge of VDU-related ergonomics was one of the most salient problems in modern or recently renovated offices.

Other concerns in renovated offices were insufficient ventilation (adjustment and air flow problems as well as problems with defective separation of fresh and used air), problems with lighting (glare, unsuitable colour temperature of the luminaries, low or no daylight factors, etc.), poor microclimate, particularly in summer, and noise. Those problems were not addressed when planning renovation work in the offices.

There are numerous unrenovated offices in Estonia, too, with poor microclimate (cold air),

\section{noise $(89.5 \mathrm{~dB}(A))$ \\ air temperature}

$\left(26.7^{\circ} \mathrm{C}\right)$

physical overload air humidity

$(38.0 \%)$

textile dust

$\left(1.0 \mathrm{mg} / \mathrm{m}^{3}\right)$ lighting

$(500-1900 \mathrm{~lx})$

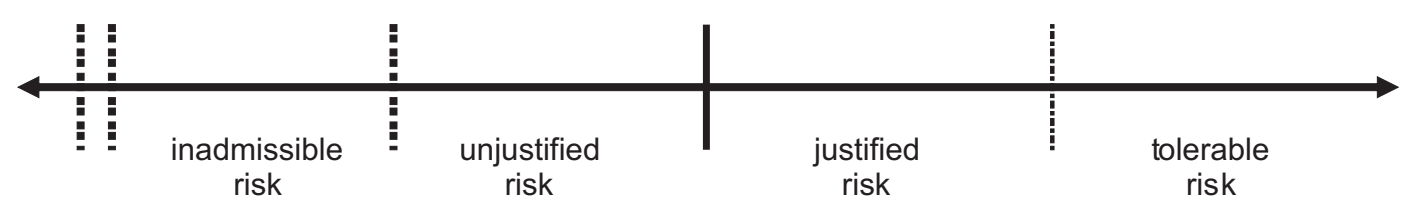

Figure 3. Assessment of the working conditions with a simple risk assessment method in the textile industry. 


$\begin{array}{ccc}\text { transport noise } & \text { poor ergonomics } & \text { air humidity } \\ (>55 \mathrm{~dB}(A) \text { inside) } & \text { (VDU work- } & (40-60 \%) \\ \text { bright sunlight } & \text { stations) } & \\ \text { air temperature } & \\ \left(>30^{\circ} \mathrm{C}\right) & \end{array}$

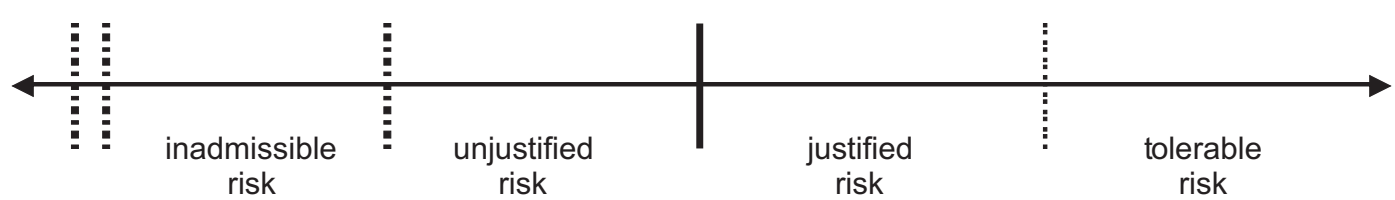

Figure 4. Assessment of the working conditions in offices in summer. Notes. VDU-video display unit.

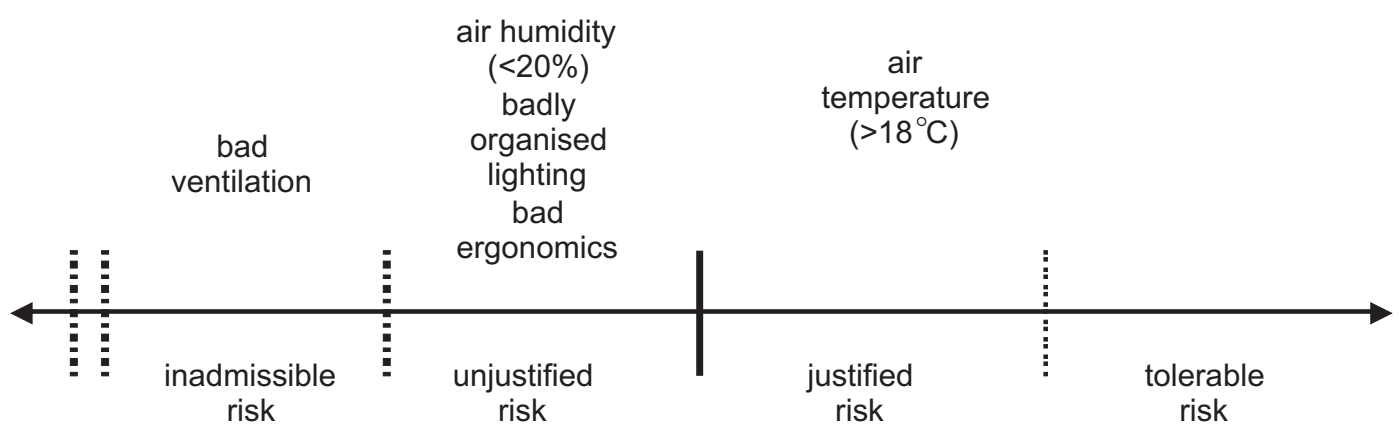

Figure 5. Assessment of the working conditions in offices in winter.

ventilation problems because of dirty ventilation ducts which are not cleaned regularly, insufficient lighting, and poor ergonomics.

It is important to consider these problems during planning renovation as otherwise, workers' concerns will emerge with even greater urgency when they have to face the same problems in renovated areas. The workers' age also has to be taken into account, because older personnel tend to have different concerns than younger ones.

The 5-step simple, flexible risk assessment model was used for the assessment of the working conditions in offices in summer (Figure 4) and in winter (Figure 5). Different offices were surveyed in summer and winter.

\subsection{Conclusions on Exposure}

Working conditions in the Estonian working environment vary a great deal. In the best cases, economically successful firms are able to supply their workers with a sauna, solarium, gym, etc., but in others, conditions can be at the opposite extreme, e.g., workers have to work in freezing conditions (at $0{ }^{\circ} \mathrm{C}$ inside the room in winter) or workers' personal clothing is hung where there are odorous chemicals.

Working conditions tend to be better in commerce and banking; however, in manufacturing, they may still be quite poor. Moreover, there is considerable regional variation. In the capital and the surrounding areas enterprises have the capacity and finances to invest in workers' health more than in the other regions. However, despite the distance which remains to travel before the best Scandinavian practice becomes general, working conditions are improving from year to year.

New Estonian legislation on occupational health and safety which is based on EU directives has produced a positive, if still uneven, impact in terms of improving working conditions and increasing the level of safety culture. Workers themselves appear to have begun to realize that OHS cannot be left entirely to safety personnel if there is to be active implementation of safety and health measures. The spread of information throughout the organization and a positive attitude towards safety among the workforce are extremely important. 
More essential problems occur at the level of SMEs (the overwhelming majority of Estonian enterprises), where the problems are often dealt with only after there has been an accident. Large enterprises usually employ a specialist in OHS educated in legislation, management of hazards and in prevention.

Many workers in Estonia do not report symptoms of ill health and continue to show up for work. In addition, individuals continue to accept their problems as a consequence of aging or fatigue and do not often perceive their problems as work-related.

\subsection{Workers' Opinion on Working Conditions}

During visits to enterprises and offices to measure the working environment and to assess risk, an attempt was made to elicit employee views. In $50 \%$ of cases ( 70 enterprises) a short questionnaire (in Estonian and Russian) was administered; response rate was $24 \%$ (i.e., 356 completed questionnaires). The results are given in Figures 6-8. Ergonomic hazards were to be ranked on a 4-point scale: do the following hazards create a problem for you often, sometimes, seldom or never.

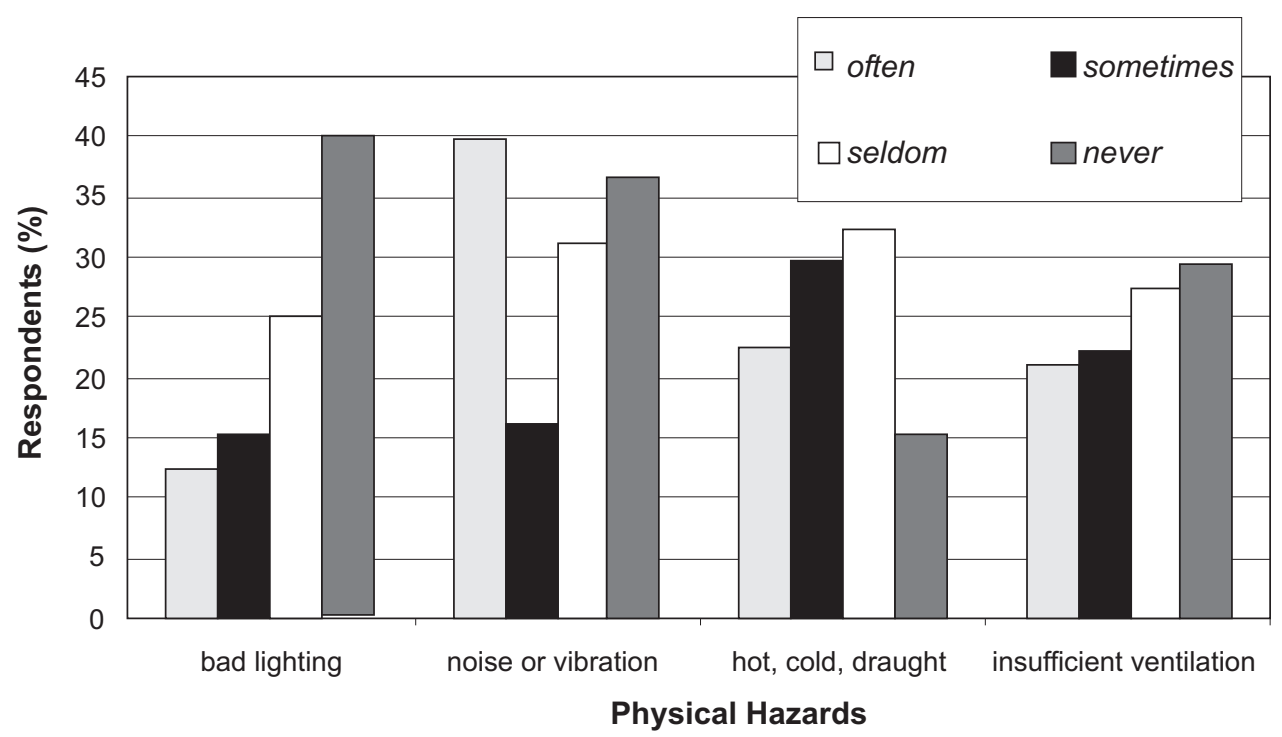

Figure 6. Workers' opinions $(n=356)$ on physical hazards in the working environment.

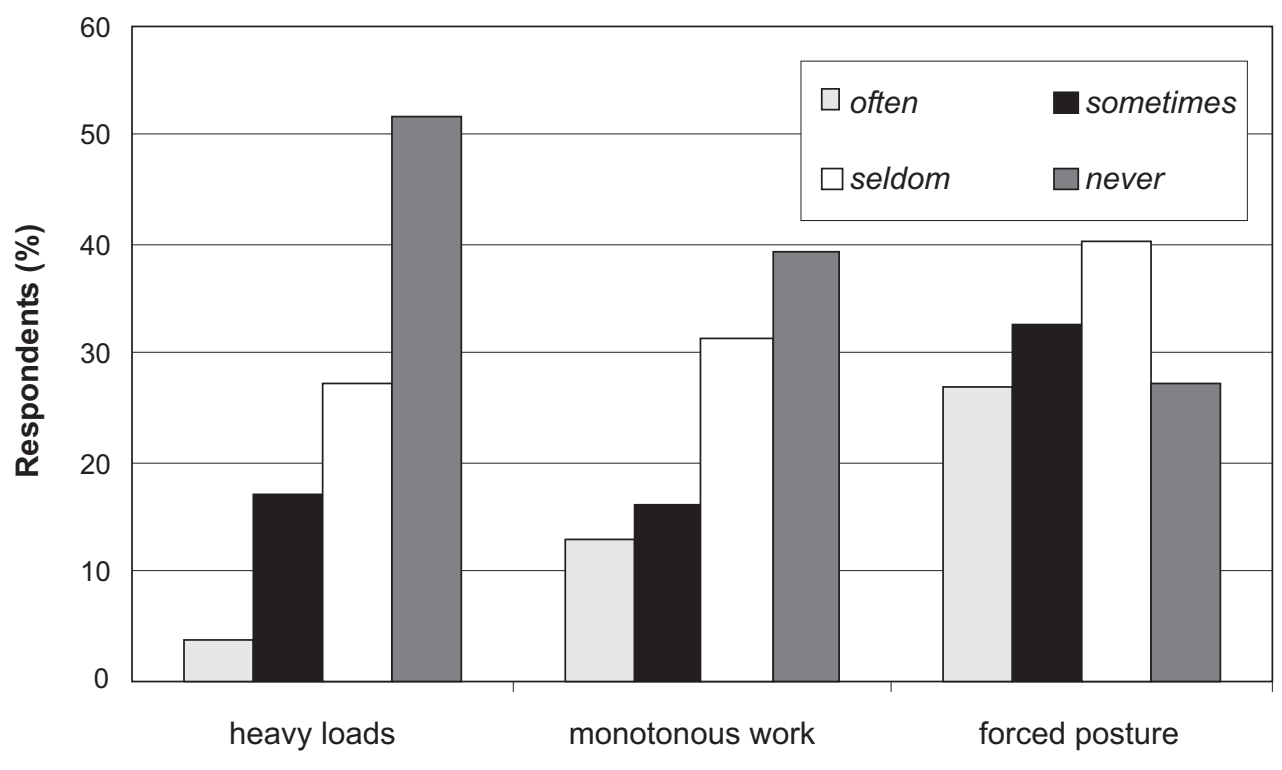

Ergonomic Hazards

Figure 7. Workers' opinions $(n=356)$ on ergonomic hazards in the working environment. 


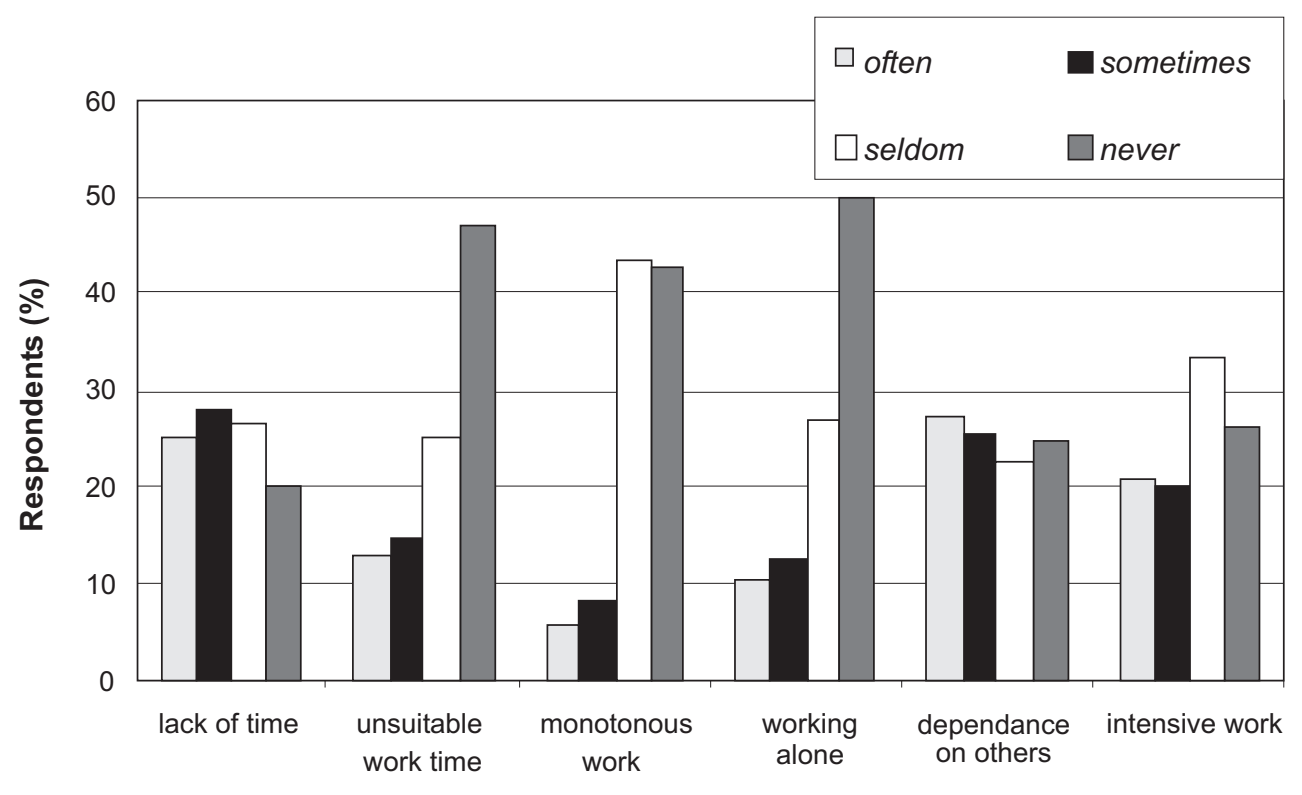

Physical Hazards

Figure 8. Workers' opinions $(n=356)$ on psychological hazards in the working environment.

Workers mostly complained about excessive noise, forced postures, lack of time (due to intensive working pace) and the dependence in the work process on colleagues. One in five complained of the intensity of the work process itself.

The following conclusions can be drawn on the basis of a comparison of those figures with data from the Baltic Working Environment and Labour (BWEL) survey [21].

- Both studies produced the same results regarding problems with lighting: poor lighting in the current study elicited often as a problem for $12.5 \%$ of workers and sometimes for $15.0 \%$ of workers; in BWEL poor lighting was a serious problem for $8.2 \%$ of workers and a minor problem for $24.9 \%$ of workers. Some differences appear when comparing the influence of noise: in the current study the noise and vibration load affected often $40.0 \%$ and sometimes $15.0 \%$ of workers; in BWEL noise and vibration were a serious problem only for $11.2 \%$ and a minor problem for $27.8 \%$ of workers. Noise is a problem characteristic for many manufacturing branches such as printing, wood processing, textile industries, whereas it might not be a problem for office workers. As the current study examined mainly noisy industrial branches, the differences might have resulted from this factor. Microclimate problems arose more explicitly in the current study than in the BWEL survey as extreme temperatures disturbed often $22.5 \%$ and sometimes $30.0 \%$ of workers, while in BWEL inappropriate or inadequate air temperature control was a serious problem for $10.7 \%$ and $a$ minor problem for $22.4 \%$ of workers.

- Both studies indicated that Estonian employees frequently faced poor ergonomic conditions at work: the most negative factor in the current study was forced postures that affected often $28.0 \%$ and sometimes $32.0 \%$ of workers. In the BWEL survey, the comparable factor was overall fatigue that affects $33.1 \%$ of the Estonian workers.

- The current study showed that according to the workers lack of time (often $25 \%$ and sometimes $28.0 \%$ of workers) and the dependence of the work process on colleagues $(28.0 \%$ of workers often and $26.0 \%$ sometimes) were the most negative factors related to psychological conditions. In the BWEL study, psychological 
factors were summarized with one indicator, stress, which affects $24.4 \%$ of workers.

\section{CONCLUSIONS}

The European Commission has set for itself an ambitious overall objective: to reduce by $25 \%$ the total incidence rate of accidents at work in the EU in 2007-2012. This will be a great challenge for Estonian OHS.

The Estonian working environment has changed considerably during the last 10 years and is continuing to evolve as a result of the following trends much in line with broader European trends identified in the key EU strategy documents on OHS: new technologies, growing use of information and communication technology, growth in the service sector, more specific risks (ergonomics and personal contact with people, stress, violence); new forms of work, such as telework, self-employment, subcontracting, temporary employment; ageing workforce; increasing interest in autonomous work; changing management structures, organizations have become flatter, smaller and leaner; a growing number of SMEs, in which health and safety knowledge and resources are often insufficient; increasing work pace and work load.

Even though rapid improvement has been made in the field of OHS in Estonia in recent years, there are still challenges ahead. The OHS infrastructure in Estonia is still poor. The effectiveness of the present OHS system in Estonia is undermined by the insufficient coverage of occupational health services, lack of political will to meet EU OHS requirements, lack of relevant statistical data and research activities in the field, poor quality of risk assessment and the continuing absence of an insurance act for occupational accidents and diseases which effectively places the burden of compensation, support and rehabilitation as a result of workplace injury or ill health on the individual worker and their family.

Further research in OHS would be helpful to have better information on occupational accidents and diseases, risk factors, good practice, and safety management systems. This would make it possible to increase the effectiveness of an OHS monitoring system to include quantitative as well as qualitative data. OHS monitoring should support knowledge-based administrative decisions on legislation, law enforcement, research and setting of priorities, monitoring changes and identifying emerging risks, as well as designing and setting up corrective and better preventive measures. There is also a need for further identification and anticipation of emerging of OHS-related risk and an evaluation of many safety measures that are in place or planned. To achieve positive results, it is necessary to strengthen the national OHS system in Estonia as well as the public's awareness through tripartite collaboration. This includes legal provisions, enforcement, compliance and labour inspection capacity and capability, knowledge management, information exchange, research and support services. Finally, the suppresion of good practice in OHS requires that representatives of the workforce be empowered in the process of OHS management at enterprise and workplace level. Here, the challenges facing Estonia are not unique, and the example of nearby Finland may reveal new avenues for employee participation in OHS. In this respect, the gulf between neighbours still remains to be crossed.

\section{REFERENCES}

1. Woolfson C, Calite D. New European Community strategy for health and safety: the elephant in the room. Int $\mathrm{J}$ Occup Environ Health. 2007;13(3):342-55.

2. European Commission. DirectorateGeneral V. Guidance on risk assessment at work. Luxembourg: Office for Official Publications of the European Communities; 1996.

3. Occupational Health and Safety Act. State Gazette in Estonia RTI. 1999;(60):616. Retrieved January 30, 2009, from: http:// www.legaltext.ee/text/en/X30078K4.htm

4. British Standards Institution (BSI). Guide to occupational health and safety management systems (Standard No. BS 8880:1996). 1996; London, UK: BSI. 
5. Pekkarinen A. Learning from work accidents and risk assessment forms the basis for safety promotion. Barents Newsletter on Occupational Health and Safety. 2007;10:3-4.

6. Rantanen S. Chemical risk assessment. Days of Occupational Health 23-24.10.2001. Helsinki, Finland: Finnish Institute of Occupational Health; 2001. In Finnish.

7. Reinhold K, Tint P, Kiivet G. Risk assessment in textile and wood processing industry. IJRQSE. 2006;13 (2):115-25.

8. National Labour Inspectorate (Estonia). The year report 2002. Tallinn, Estonia: National Labour Inspectorate. Retrieved January 30, 2009, from: http://www.ti.ee/ index.php?page $=236 \&$

9. National Labour Inspectorate (Estonia). The year report 2006. Tallinn, Estonia: National Labour Inspectorate. Retrieved January 30, 2009, from: http://www.ti.ee/public/ files/2006\%20aasta\%20aruanne(1).pdf

10. Commission of the European Communities. Communication from the commission. Adapting to change in work and society: a new Community strategy on health and safety at work 2002-2006 (COM(2002) 118 final); 2002. Retrieved January 8, 2008, from: http://ec.europa.eu/employment_ social/news/2002/mar/new_strategy_en.pdf

11. Government of the Republic. Occupational health and safety requirements for workplace. Regulation No. 176 of 14 June 2007. State Gazette in Estonia RTI. 2007; (42):305.

12. Government of the Republic. Occupational health and safety requirements for use of work equipment. Regulation No. 13 of 11 January 2000. State Gazette in Estonia RTI. 2000;(4):30.

13. Republic of Estonia. Working and rest time act. Passed 24 January 2001, State Gazette in Estonia RTI. 2001;(17):78.
14. Republic of Estonia. Employment and contracts act. Passed 15 April 1992. State Gazette in Estonia RT. 1992;(15/16):241.

15. Ministry of Social Affairs. Occupational health and safety requirements for manual handling of loads. Regulation No. 26 of 27 February 2001. State Gazette in Estonia RTL. 2001;(35):468.

16. Kempinen M, Tint P. Auditing of safety management system in Estonian mediumscale enterprises. In: Guedes Soares C, Zio E, editors. Safety and reliability for managing risk. London, UK: Taylor \& Francis; 2006. p. 773-80.

17. Järvis M, Tint P. Knowledge management. In: Pacholski LM, Trzcielinski S, editors. Ergonomics in contemporary enterprise. Madison, WI, USA; IEA Press; 2007. p. 517-34.

18. Reinhold K, Tint P. Risk assessment in manufacturing: possibilities and results. In: Pacholski LM, Trzcielinski S, editors. Ergonomics in contemporary enterprise. Madison, WI, USA; IEA Press; 2007. p. 112-23.

19. Council Directive 67/548/EEC of 27 June 1967 on the approximation of laws, regulations and administrative provisions relating to the classification, packaging and labelling of dangerous substances. OJ. 1967;196:1-98.

20. Ministry of Social Affairs. Identification, classification, packaging and labelling of dangerous chemicals. Regulation No. 64 of 11 December 1998. State Gazette in Estonia RTL. 1998;(372/373):1610.

21. Woolfson C, Calite D, Kallaste E. Employee 'voice' and working environment in post-communist New Member States: an empirical analysis of Estonia, Latvia and Lithuania. Industrial Relations Journal. 2008;39(4):314-34. 